a wide area, and for electric-welded joints the subsequent annealing process (which is very timeconsuming) is much easier.

\section{Radiophysics Laboratory, Sydney}

ONE of the Divisions of the Commonwealth Scientific and Industrial Research Organization of Australia is the Radiophysies Laboratory, situated in the grounds of the University of Sydney, and the chief of the Division is Dr. E. G. Bowen. The four main fields of research in the Laboratory are radio astronomy, cloud and rain physics, automatic computation and the development of radio aids to navigation, and in a very attractive and wellillustrated brochure, entitled "Research Activities of the Radiophysics Laboratory" (pp. 36. Melbourne: C.S.I.R.O., 1952), a brief account is given of the Laboratory's current work under these four separate headings. The section on radio-astronomy is mainly concerned with the study of radio noise from the sun and outer space. The design of a new solar radio-spectroscope, now under construction, which is to cover the frequency-range $40-240 \mathrm{Mc} . / \mathrm{s}$., and a 32-element interferometer, which will be used at decimetre wave-lengths for the location of sources of solar radio noise, are described. Investigations to determine the positions and characteristics of discrete sources of cosmic noise and the techniques involved are discussed, and an interesting study is outlined of the temperature and structure of the ionospheric $D$-layer by an application of a method first used in radio astronomy to measure the thermal emission from the solar corona. The study by micro-wave radar of rain formation and cloud-seeding experiments for rain-making are the main items in the rain and cloud physics section, and details of the binary type Mk. I digital computer which hos now been in use for about a year are given in the section on automatic computation. In the final section, dealing with radio aids to navigation, are described two short navigational aids, the "Distance Measuring Equipment" for aircraft and the "Multiple Track Range" providing a number of flight tracks to and from an airport, and, in addition, a recently developed microwave direction-finding apparatus operating at a wave-length of $3.2 \mathrm{~cm}$. The accounts of the work of each section are terminated by a detailed list of scientific papers published by its members during 1948- 52.

\section{Imperial College of Science and Technology, London : Report for 1951-52}

THE forty-fifth annual report of the Governing Body of the Imperial College of Science and Technology, London, covering the year ended July 31, 1952 (pp. 60 ; from the College, 1953), refers to the start being made on the new building for the Aeronautics Department, although the steel allocation was at that time being awaited. The creation of laboratories for mineral dressing in the Bessemer Laboratory was nearing completion and a small extension of the Department of Metallurgy was being made in the same building. The space available for expansion in the South Kensington area has been increased by purchase of the freehold of the property at 179 Queen's Gate, and an additional twenty-eight acres of land contiguous to the Field Station at Silwood Park, Sunninghill, have also been purchased. A series of lectures on general subjects for first-year undergraduate students was organized by the Dean of the City and Guilds College during 1951-52, and, with the London School of Economics and Political Science, joint postgraduate studies in technology, economics and administration have been arranged for the session 1952-53. As a further experiment in co-operation between academic staff and students, the College hours are being varied so as to leave two hours (12.30 p.m.-2.30 p.m.) on Tuesdays and Thursdays entirely freə from organized College studies. On each of these days a joint committee of staff and students is arranging functions such as discussion talks by outside experts, concerts of chamber music and general entertainments organized by student societies. Besides the statement of accounts and details of teaching and administrative staff changes, appendixes to the report include a list of publications during 1951-52, arranged under departments.

\section{Dry Rot in Wood}

A FIFTH edition of "Dry Rot in Wood", Bulletin No. 1 of the Forest Products Research Institute, by K. St. G. Cartwright and Dr. W. P. K. Findlay, has been issued under the auspices of the Department of Scientific and Industrial Research (pp. $36+8$ plates. London: H.M.S.O., $1952 ; 2 s$. net). It is said that dry rot has become very much more prevalent during the past decade, though whether this is so has not been proved; nevertheless, there must be many people who are acquainted with the appearance of dry rot in the house in floorboards and other woodwork. The attack is caused by Merulius lacxymans; moisture is necessary, and strands of the fungus can transport the moisture so that it can rot moderately dry timber once it has got a hold. Dry rot spreads easily. Like the white ant of the tropics in its search for timber, the fungus is said to be able to pass through brick or stone walls via the mortar. As to methods to combat it, the council of perfection is to have no damp spot anywhere in the house. "Leaky gutters, cracked pipes and so on should be repaired immediately. Cellars should be kept dry." Are all these precautions possible these days ? There is often a considerable delay before repairs to leaking roofs, pipes, etc., can be effected, and, though it may be feasible to keep a small cellar dry, in country houses where the cellarage may be of fair size it would be very expensive to keep them heated throughout the winter; and, in the case of the wine cellar, the cherished wine would be ruined. Nevertheless, this edition of the bulletin has been thoroughly revised, and in houses of any size it should be regarded as indispensable. No simple practical remedial measure is apparently yet available.

\section{Metals in the Service of Man}

IN the Museums Journal of May 1953, Mr. A. R. Hutchieson describes the modern treatment of the non-ferrous metals at the Royal Scottish Museum, Edinburgh. This has been arranged as a panorama of metals in the service of man. Beginning with a brief survey of their discovery and early uses, this is followed by an attractive introduction to the more technical exposition of modern extraction methods, processing and applications. Bold, colourful maps and diagrams are used, and by an imaginative selection of characteristic three-dimensional material the display has atmosphere and life. Aluminium, magnesium, nickel, copper, tin, lead and zinc have been dealt with, and the growing popularity of the new display with visitors indicates that the method of presentation has been successful. 